\title{
Simulation of N-Way Traffic Lights Using Arduino Uno Environment
}

\author{
Ogwo Eme \\ Department of \\ Computer Science, \\ Akanu Ibiam Federal \\ Polytechnic Unwana, \\ Ebonyi State, Nigeria
}

\author{
Chibuike .E. \\ Madubuike \\ Department of \\ Computer Science, \\ Akanu Ibiam Federal \\ Polytechnic, Unwana, \\ Ebonyi State, Nigeria
}

\author{
Joseph .O. Idemudia \\ Department of \\ Computer Science, \\ Akanu Ibiam Federal \\ Polytechnic Unwana, \\ Ebonyi State, Nigeria
}

\author{
Akaninyene Udo \\ Ntuen \\ Department of \\ Computer Science, \\ Akanu Ibiam Federal \\ Polytechnic \\ Unwana,Ebonyi State, \\ Nigeria
}

\begin{abstract}
Traffic is a major challenge in many cities in the world today. In many instances traffic flow is dictated by certain devices such as traffic lights. Traffic lights have become an integral part of human day-to-day life. This work focuses on the simulation of traffic light system with a microcontroller programmed on the Arduino Uno board. This system was designed to handle road traffic control as well as assisting pedestrians to move freely without auto crashes. The traffic lights simulation system was implemented using an Arduino Uno microprocessor connected to electronic circuit board. The programming platform for the simulation of the traffic light system was done using $\mathrm{C}++$ programming language while the electronic circuit used was designed with some semiconductor components such as transistors, microprocessor, resistors and light emitting diodes (LEDs) to achieve optimal performance of the traffic lights.
\end{abstract}

Keywords: Embedded System, Light Emitting Diode (LED), Microcontroller, Simulation, Traffic Light.

\subsection{INTRODUCTION}

The tremendous increase of the number of vehicles on our roads and the over-whelming array of pedestrians on road side ways call for great concern. The numerous avoidable accidents at intersections be it T-junction or 4-way-junction is acknowledged not only by government but also other users of the roads. This situation calls for remedy or assistance of some sort not only to save lives but also to ensure orderliness in our everyday life. Electronic devices, which can do services round the clock, throughout the whole season of the year, are call to play this indispensable role.

Traffic is a problem in many urban areas worldwide. In more civilized cities, traffic flows are mostly dictated by certain devices such as traffic lights. These traffic lights are often held on poles at intersections of road.

Furthermore traffic light has become an integral part of human day to day life. With the advancement in semiconductors technology and a parallel rise in innovation, embedded technology has brought about a lot of change in lighting engineering. With this motivation in mind, this work aims at designing and implementing a running model of traffic light controller which will help to control the density of vehicular movements on the road.

Traffic lights - also known as traffic signals, traffic lamps, traffic semaphore, signal lights, stop lights, and (in technical parlance) traffic control signals- as signaling devices positioned at road intersections, pedestrian crossings, and other locations to control flows of traffic [1]. Traffic lights alternate the right of way accorded to road users by displaying lights of a standard color (red, yellow/amber, and green) following a universal color code. In the typical sequence of color phases:

- The green light allows traffic to proceed in the direction denoted, if it is safe to do so and there is room on the other side of the intersection.

- The amber (yellow) light warns that the signal is about to change to red. In a number of countries among them the United Kingdom - a phase during which red and amber are displayed together indicates that the signal is about to change to green. Actions required by drivers on an amber light vary, with some jurisdictions requiring drivers to stop if it is safe to do so, and others allowing drivers to go through the intersection if safe to do so.

- A flashing yellow indication is a warning signal. In the United Kingdom, a flashing amber light is used only at pelican crossings, in place of the combined red-amber signal, and indicates that drivers may pass if no pedestrians are on the crossing.

- The red signal prohibits any traffic from proceeding.

- A flashing red indication is treated as a stop sign.

In some countries traffic signals will go into a flashing mode if the controller detects a problem, such as a program that tries to display green lights to conflicting traffic. The signal may display flashing yellow to the main road and flashing red to the side road, or flashing red in all directions. Flashing operation can also be used during times of day when traffic 
is light, such as late at night. This is the case in many American States [2].

This work focuses on the simulation of traffic light system with a microcontroller programmed on the Arduino Uno board. This system was designed to handle road traffic control as well as assisting pedestrians to move freely without auto crashes. The traffic lights simulation system was implemented using an Arduino Uno microprocessor connected to electronic circuit board.

\subsection{REVIEW OF RELATED LITERATURE}

This section discusses related literature and contributions of other authors as it relates to the topic under consideration.

The first electric traffic light was developed in 1912 by Lester Wire, a policeman in Salt Lake City, Utah, who also used red-green lights. On 5 August 1914, the American Traffic Signal Company installed a traffic signal system on the corner of East 105th Street and Euclid Avenue in Cleveland, Ohio [3]. It had two colors, red and green, and a buzzer, based on the design of James Hoge, to provide a warning for color changes. The design by James Hoge allowed police and fire stations to control the signals in case of emergency. The first four-way, three-color traffic light was created by police officer William Potts in Detroit, Michigan in 1920.

Los Angeles installed its first automated traffic signals in October 1920 at five locations on Broadway. These early signals, manufactured by the Acme Traffic Signal Co., paired "Stop" and "Go" semaphore arms with small red and green lights. Bells played the role of today's amber or yellow lights, ringing when the flags changed - a process that took five seconds. By 1923 the city had installed 31 Acme traffic control devices. The Acme semaphore traffic lights were often used in Warner Bros. Looney Tunes and Merrie Melodies cartoons for comedic effect due to their loud bell [4].

According to [5], the first interconnected traffic signal system was installed in Salt Lake City in 1917, with six connected intersections controlled simultaneously from a manual switch. Automatic control of interconnected traffic lights was introduced March 1922 in Houston, Texas.

According to [1], traffic control systems are the most visible element of the urban infrastructure. They are not just physical systems like telephones or sewers or streets, although their technological elements, traffic lights, signs, and painted pavements, fit that description. Rather, they are systems that attempt to impose a strong social control over the most fundamental of human behaviors, whether to move or be still. Traffic engineers must control police, drivers, and pedestrians. For most other elements of the urban infrastructure, controlling the behavior of users did not constitute the primary goal of designers. For traffic engineers, understanding and manipulating the behavioral patterns of drivers and pedestrians (a group that included not just walkers, but people using the street for play, social gatherings, and commerce) proved to be a more important problem than the control mechanisms themselves. Traffic engineers learned rapidly to pay careful attention to ergonomics, the interface between people and machines.

Reference [6], advocated for the use of clever traffic light as a solution for traffic control for pedestrian crossing. According to them the sequence of switching signals of usual traffic light simplistically may be represented in the following ways:

- drivers go;

- both (drivers and foot-passengers) wait;

- foot-passengers go;

- both (drivers and foot-passengers) wait;

- repeating cycle.

Clever traffic-light works not in the least like that its possession of information about cars on the road and footpassengers on pedestrian crossing. In presence of some footpassengers and cars, traffic-light works like common traffic-light. If there are no cars, but foot-passengers are waiting on pedestrian crossing, it will indicate the green light for the pedestrian until at least one car appears, and vice versa. If there is neither car no foot-passengers, green light will be indicated for cars because they need more time to slow down and to pick up speed to continue the motion.

Reference [7] viewed optics and lighting as traditionally incandescent and observed that halogen bulbs where used in constructing traffic light. Because of the low efficiency of the light output and a single point of failure (Filament burnout) municipalities are increasing retrofitting traffic signals with LED arrays. Unlike incandescent and halogen bulbs, which generally get hot energy and melt, LEDs consume less power which have increased light output and in the event of an individual LED failure, still operate with a reduced light output. With the used of optics, the light pattern of LED array can be comparable to the pattern of an incandescent or halogen bulb.

According to [8], the conventional light system such as traffic signal lighting which is still common in some areas, utilizes a standard light bulb typically 67 watts, 69 watts or 115 watts medium-based light bulbs (house hold lamp in the US). Light bulb provides the illumination light then bounces off a mirrored glass or polished aluminum reflector bowl, and out through a polycarbonate plastic or glass signal lens. In some signals, these lenses were cut to include a specific refracting pattern. Crouse-Hinds is one notable company for this practice between the 1930s and 1950s, they utilized a beaded prismatic lens with a "Smiley" pattern embossed into the bottom of each lens.

Traffic light design in the United States, that traffic lights are currently designed with lights approximately 12 inches $(300 \mathrm{~mm})$ in diameter. Previously the standard has been 8 inches $(200 \mathrm{~mm})$, however, those are slowly being out in favor of the larger and more-visible 12inch lights. Variations used have also include a hybrid design which had one or more 12inch light alone with one or more lights of 8 inch $(200 \mathrm{~mm})$ on the same light for example, those " $12-8$ 8 " (along with 8-8-8) light are standard in most jurisdictions in Ontario, Manitoba and British Columbia (i.e., the red light is 12 and others 8, making the read more prominent) [9].

It had been observed that as technological advancement with technologies in developed countries continuing to 
advance, there is now an increasing move to develop and implement smart traffic light on the roads. These are basically intelligent systems that try to communicate with cars to alert drivers of impending light changes and reduce motorists waiting time considerably. Trails are currently being conducted for the implementation of these advanced traffic light but there are still many hurdles to widespread use that need to be address, one of the fact that not a lot of cars yet have the required system to communicate intelligently with these lights [10].

A microcontroller (abbreviated with $\mu \mathrm{C}$ or $\mathrm{MCU}$ ) is a small computer on a single integrated circuit containing a processor core, memory and programmable input and output peripherals. The program memory in the form of NOR flash or EPROM is also included on the chip, as well as a typically small amount of RAM. Microcontroller is designed for embedded application, in contrast to the microprocessor used in personal computers or other general purpose applications. Microcontrollers are used in automatically controlled products and devices, such as automobile engine control system, implantable medical devices, remote controls, office machines electronic appliances, power tools, toys and other embedded systems. By reducing the size and cost compared to a design that use a separate microprocessor, memory input and output devices, microcontrollers make it economical to digitally control even more devices and processes. Mixed signal microcontrollers are common integrating analog components needed to control non-digital electronic system [11].

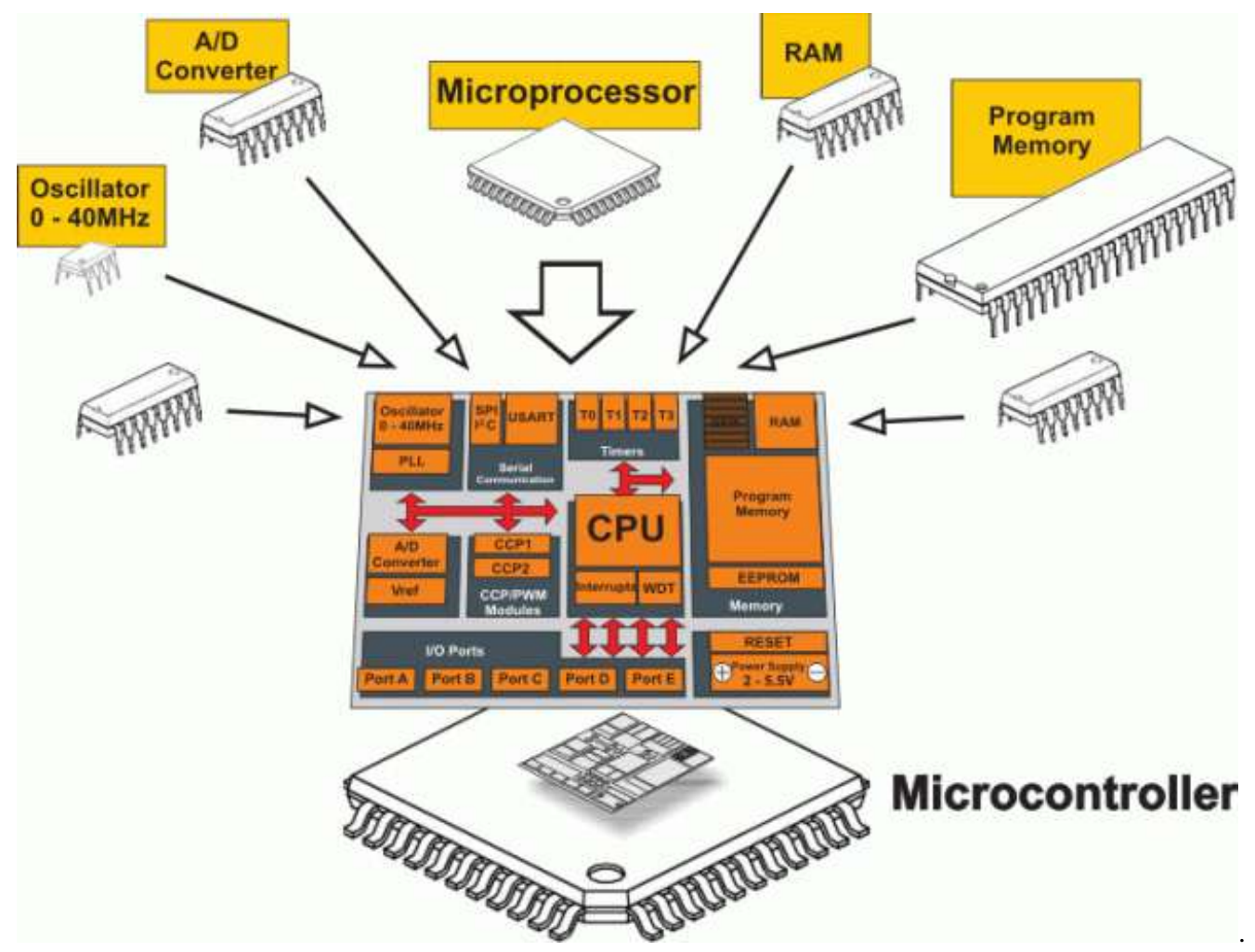

Fig.1: Block Diagram of a microcontroller Source: [12]

As advancement in embedded systems and microcontroller continues to improve the existing road traffic system, it has become imperative for different regions and countries to develop their low cost indigenous system which will support their local traffic policy and will be easy to maintain. The need to integrate local content in traffic light system has necessitated this Arduino uno microcontroller based traffic light simulation.

\subsection{METHODOLOGY}

In this work, Arduino Uno microcontroller was used to simulate the flow of signals in the traffic light. Arduino, in general is an open source platform targeting hobbyists. An open source is a method where the developers of a software/hardware give the end user access to their end products design and implementation. This means that the end users have right to modify/change the way the software looks/works and redistribute it. Examples of open source software are Linux operating system, free PBC, and open BSD etc. Furthermore, Arduino is an open source hardware and software platform which uses Atmel microcontroller as core hardware component and $\mathrm{C}$ or $\mathrm{C}++$ as core software language and which is used to control LEDs, motors, displays and any hobby projects. 


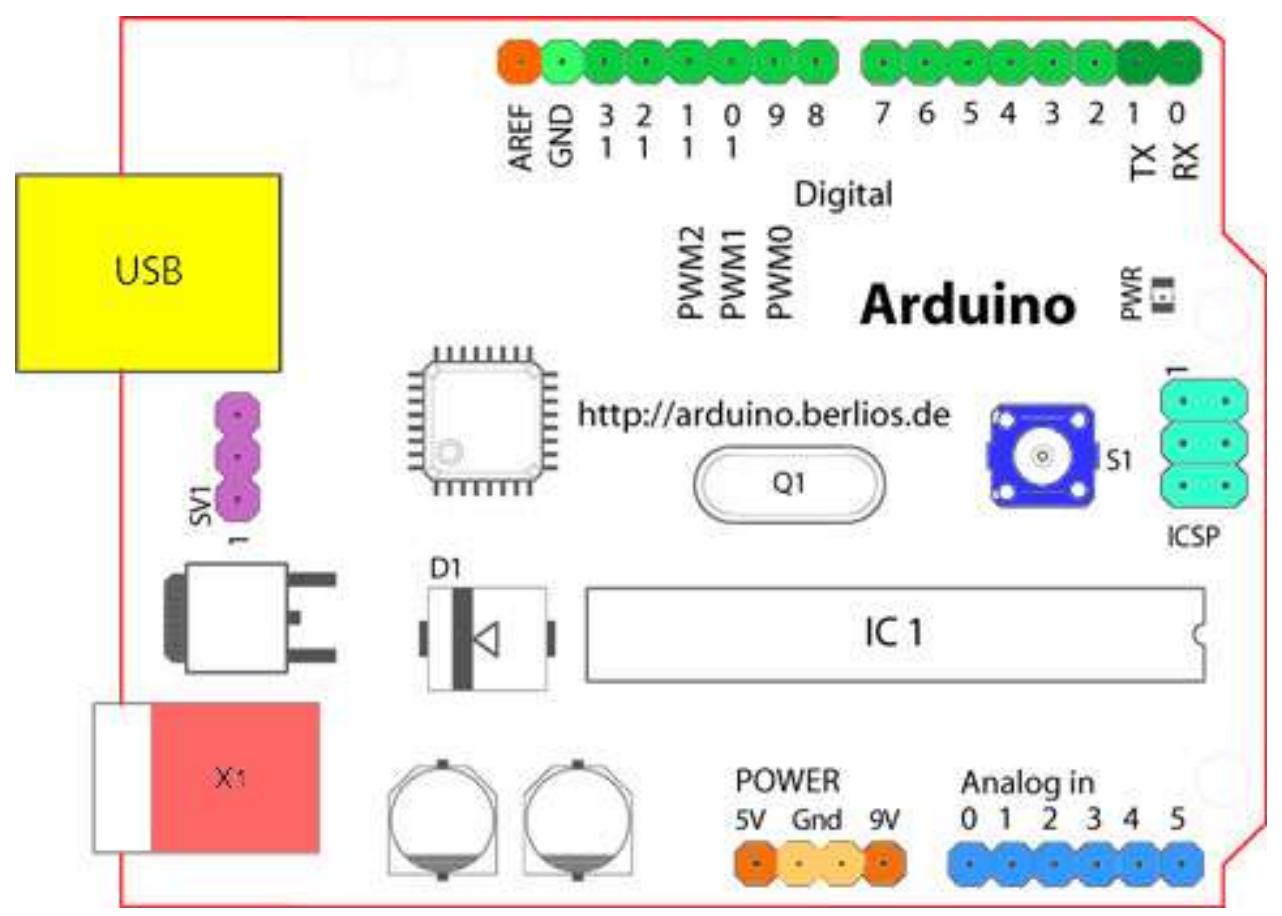

Fig.2: Pin Diagram of an Arduino Uno Board Source: [13]

Starting clockwise from the top center:

- Analog Reference pin (orange)

- Digital Ground (light green)

- Digital Pins 2-13 (green)

- Digital Pins 0-1/Serial In/Out - TX/RX (dark green) - These pins cannot be used for digital i/o (digitalRead and digitalWrite) if you are also using serial communication (e.g. Serial.begin).

- Reset Button - S1 (dark blue)

- In-circuit Serial Programmer (blue-green)

- Analog In Pins 0-5 (light blue)

- Power and Ground Pins (power: orange, grounds: light orange)

- $\quad$ External Power Supply In (9-12VDC) - X1 (pink)

- Toggles External Power and USB Power (place jumper on two pins closest to desired supply) - SV1 (purple)

- USB (used for uploading sketches to the board and for serial communication between the board and the computer; can be used to power the board) (yellow)

The Arduino software consists of two parts: Arduino BootLoader and Arduino IDE. Arduino Boot-Loader is a piece of code residing inside the microcontroller which make the controller special and gives it the power of integration to the Arduino IDE and the Arduino board. The Arduino IDE has a compiler, serial monitor etc. Arduino language is a variant of $\mathrm{C}++$ at least it looks like $\mathrm{C}++$ Programs.

Apart from the basic Arduino, other tools that were used include:
- A red, yellow and green LED.

- A breadboard.

- Resistors for the LEDs (220 Ohms).

- Connecting wires.

- A pushbutton switch.

- A high value resistor (10k).

The output terminal can either be the source or the sink current. The maximum sink or source current is about 40MA. The high output is about $0.5 \mathrm{v}$ below $\mathrm{V}_{\mathrm{cc}}$ while the low output voltage is about $0.1 \mathrm{~V}$ about ground for load current below $25 \mathrm{~mA}$. The positive voltage supply terminal can take any voltage between $+5 \mathrm{v}$ and $+18 \mathrm{v}$.

\subsection{SYSTEM DESIGN}

This is aimed at producing a specification that will enable the controller to keep accurate implementation of the new system. The design is based on the simulation of a workable traffic light control system using an Arduino Uno Microcontroller as illustrated by the schematic diagram in Fig. 2.

\subsection{Input Design}

The input to the system is through sending of digital signals in the Arduino IDE. This is done by implementing digital write and the delay of signals using the delay time in milli-seconds since the Arduino understands this. Therefore, the Green was delay for $30,000 \mathrm{~m}_{\mathrm{s}}($ i.e $15 \mathrm{~s}$ ), then the yellow will blink for about five times each in $250 \mathrm{~m}_{\mathrm{s}}$ (i.e. $0.25 \mathrm{~s}$ ) which will display at the $\mathrm{N}$ - cross Intersection.

The Assembly was done by programming the Arduino board which is used to display the LEDs at each function. The LEDs were soldered on a PBC which are hung on the plastic with connectors passing through to the Arduino output pins. 


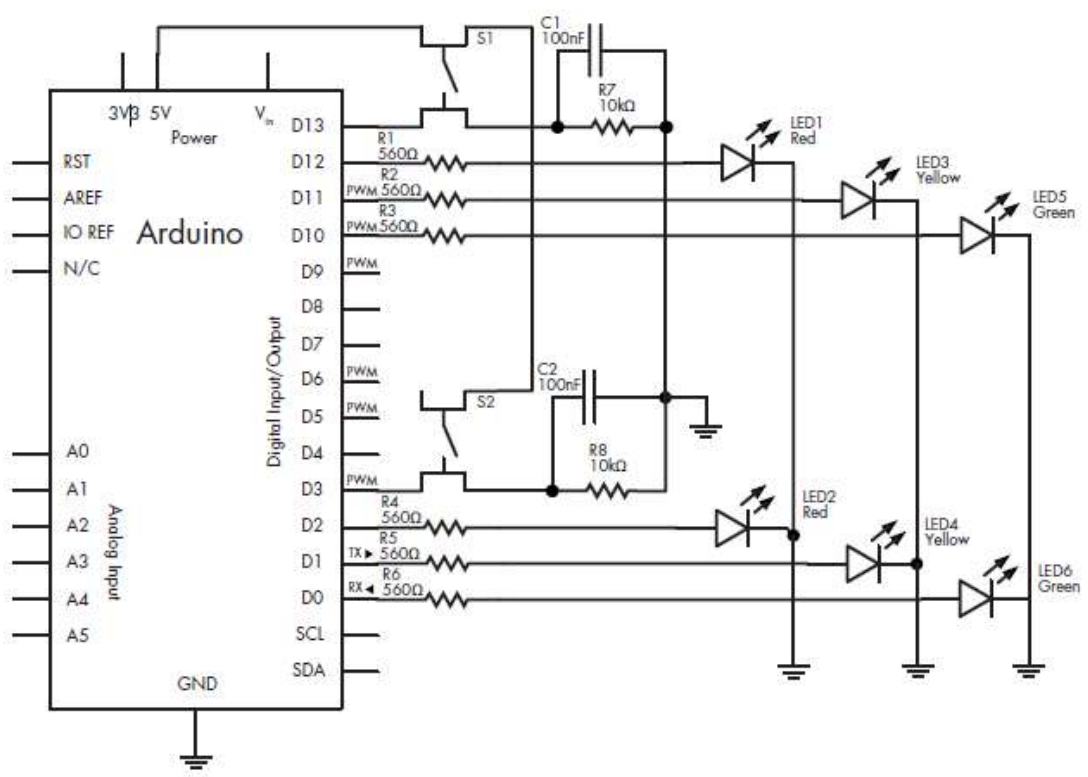

Fig.3: The schematic design of the Arduino uno microcontroller traffic system

\subsection{Simulation of the Traffic Light LEDs}

For purpose of the design, the display panel is made up of Light Emitting Diodes (LEDS). The display is used to indicate the status of the decoded counter and for performing the purpose for which it is meant to perform i.e. controlling the movement of traffic. Each status of the display contains three LEDs. Each lane has one status facing it, the RED indicting "STOP" the yellow means "READY" and the Green means "MOVE" or "GO".

The duration of the various sections of the simulated traffic lights was done through the programming of the Arduino Uno embedded microprocessor using $\mathrm{C}++$ programming language. The sample codes below show the sample source codes for the LEDs of the traffic lights.

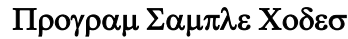

$/ / \imath v \imath \imath \alpha \lambda \imath \zeta \imath v \gamma \tau \eta \varepsilon \pi \imath v \sigma$

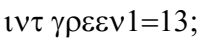

$i v \tau \psi \varepsilon \lambda \lambda \mathrm{o \omega} 1=12$;

$1 v \tau \rho \varepsilon \delta 1=11$

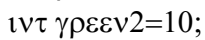

iv $\tau \psi \varepsilon \lambda \lambda \mathrm{o} \omega 2=9$;

$\operatorname{lv} \tau \rho \varepsilon \delta 2=8$;

$\imath v \tau \gamma \rho \varepsilon \varepsilon \vee 3=7$

$i v \tau \psi \varepsilon \lambda \lambda \mathrm{o \omega} 3=6$;

$\operatorname{\imath v} \tau \rho \varepsilon \delta 3=5$;

$/ / \sigma \varepsilon \tau \tau \imath \vee \gamma \cup \pi \tau \eta \varepsilon \sigma \tau \alpha \tau \nu \sigma$ oф $\tau \eta \varepsilon \pi \iota v \sigma$

$\varpi 01 \delta \sigma \varepsilon \tau \cup \pi()$

\{

$\pi \mathrm{\imath} \operatorname{Mo} \delta \varepsilon(\gamma \rho \varepsilon \varepsilon v 1$, OYTПYТ);

$\pi \mathrm{\imath} \operatorname{Mo} \delta \varepsilon(\psi \varepsilon \lambda \lambda \mathrm{o \omega} 1, \mathrm{OYT \Pi YT})$;

$\pi \imath v \operatorname{Mo} \delta \varepsilon(\rho \varepsilon \delta 1, \mathrm{OYT \Pi YT);}$

$\pi \imath v \operatorname{Mo\delta } \varepsilon(\gamma \rho \varepsilon \varepsilon v 2$, OYТПYТ);

$\pi \mathrm{\imath} \operatorname{Mo} \delta \varepsilon(\psi \varepsilon \lambda \lambda \mathrm{o \omega} 2, \mathrm{OYT \Pi YT})$;

$\pi \imath v \operatorname{Mo} \delta \varepsilon(\rho \varepsilon \delta 2$, OҮТПҮТ);

$\pi \imath \mathrm{Mo \delta} \varepsilon(\gamma \rho \varepsilon \varepsilon v 3$, ОҮТПYТ); $\pi \imath v \operatorname{Mo\delta } \varepsilon(\psi \varepsilon \lambda \lambda \mathrm{o \omega} 3, \mathrm{OYT \Pi YТ)}$

$\pi \imath v \operatorname{Mo} \delta \varepsilon(\rho \varepsilon \delta 3, \mathrm{OYT \Pi YT)}$;

\}

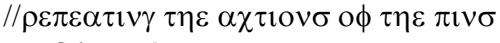
$\varpi 01 \delta \lambda \circ 0 \pi()$

\{

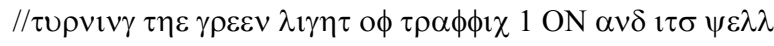
o $\alpha \nu \delta \rho \varepsilon \delta$ ОФФ

$\delta \imath \gamma \iota \tau \alpha \lambda \Omega \rho \imath \tau \varepsilon(\gamma \rho \varepsilon \varepsilon v 1, \mathrm{HI} \mathrm{H})$;

$\delta 1 \gamma \imath \tau \alpha \lambda \Omega \rho \imath \tau \varepsilon(\psi \varepsilon \lambda \lambda \mathrm{o} \omega 1, \Lambda \mathrm{O} \Omega)$;

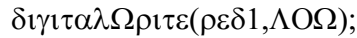

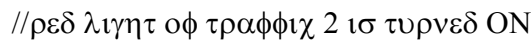

$\delta i \gamma ı \tau \alpha \lambda \Omega \rho \imath \varepsilon \varepsilon(\gamma \rho \varepsilon \varepsilon v 2, \Lambda \mathrm{O} \Omega)$;

$\delta i \gamma \imath \tau \alpha \lambda \Omega \rho \imath \tau \varepsilon(\psi \varepsilon \lambda \lambda \mathrm{o} \omega 2, \Lambda \mathrm{O} \Omega)$;

$\delta \imath \gamma \imath \tau \alpha \lambda \Omega \rho \imath \tau \varepsilon(\rho \varepsilon \delta 2, H I \Gamma H)$;

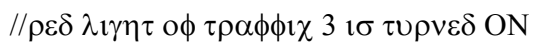

$\delta \imath \gamma \imath \tau \alpha \lambda \Omega \rho \imath \tau \varepsilon(\gamma \rho \varepsilon \varepsilon v 3, \Lambda \mathrm{O} \Omega)$;

$\delta i \gamma \imath \tau \alpha \lambda \Omega \rho \imath \tau \varepsilon(\psi \varepsilon \lambda \lambda \mathrm{o} \omega 3, \Lambda \mathrm{O} \Omega)$;

$\delta \imath \gamma \imath \tau \alpha \lambda \Omega \rho \imath \tau \varepsilon(\rho \varepsilon \delta 3, H І \Gamma H)$;

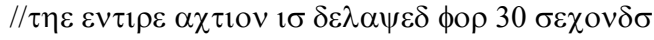
$\delta \varepsilon \lambda \alpha \psi(30000)$;

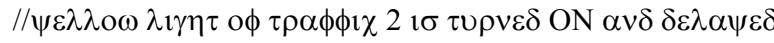
фо $10 \sigma \varepsilon \chi о \vee \delta \sigma$

$\delta i \gamma ı \tau \alpha \lambda \Omega \rho \imath \tau \varepsilon(\psi \varepsilon \lambda \lambda \mathrm{o} \omega 2, \mathrm{HІ \Gamma Н})$;

$\delta \varepsilon \lambda \alpha \psi(10000)$

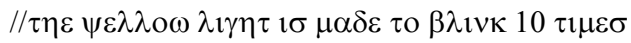
$\phi \circ \rho(\imath v \tau \imath=1 ; 1<10 ; 1++)$

\{

$\delta \imath \gamma \iota \tau \alpha \lambda \Omega \rho \imath \tau \varepsilon(\psi \varepsilon \lambda \lambda \mathrm{o} \omega 2, \mathrm{HI} \mathrm{H})$;

$\delta \varepsilon \lambda \alpha \psi(250)$;

$\delta \imath \gamma \iota \tau \alpha \lambda \Omega \rho \imath \tau \varepsilon(\psi \varepsilon \lambda \lambda \circ \omega 2, \Lambda \mathrm{O} \Omega)$ 
$\delta \varepsilon \lambda \alpha \psi(250)$

\}

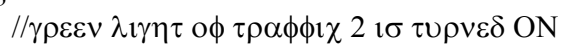

$\delta i \gamma \imath \tau \alpha \lambda \Omega \rho \imath \tau \varepsilon(\gamma \rho \varepsilon \varepsilon v 2, \mathrm{HІГН})$;

$\delta i \gamma \imath \tau \alpha \lambda \Omega \rho \imath \tau \varepsilon(\psi \varepsilon \lambda \lambda \mathrm{o} \omega 2, \Lambda \mathrm{O} \Omega)$;

$\delta 1 \gamma \imath \tau \alpha \lambda \Omega \rho \imath \tau \varepsilon(\rho \varepsilon \delta 2, \Lambda O \Omega)$;

$/ / \rho \varepsilon \delta \lambda \imath \gamma \eta \tau$ oф $\tau \rho \alpha \phi \phi i \chi 11 \sigma \tau u \rho v \varepsilon \delta$ ON

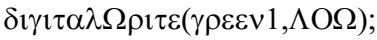

$\delta i \gamma \iota \tau \alpha \lambda \Omega \rho \imath \tau \varepsilon(\psi \varepsilon \lambda \lambda \mathrm{o \omega} 1, \Lambda \mathrm{O} \Omega)$;

$\delta 1 \gamma \imath \tau \lambda \lambda \Omega \rho \tau \varepsilon(\rho \varepsilon \delta 1, \mathrm{HI} \Gamma \mathrm{H})$

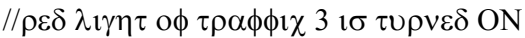

$\delta i \gamma \imath \tau \alpha \lambda \Omega \rho \imath \tau \varepsilon(\gamma \rho \varepsilon \varepsilon v 3, \Lambda \mathrm{O} \Omega)$;

$\delta \imath \gamma \imath \tau \alpha \lambda \Omega \rho \imath \tau \varepsilon(\psi \varepsilon \lambda \lambda \mathrm{o} \omega 3, \Lambda \mathrm{O} \Omega)$;

$\delta i \gamma ı \tau \alpha \lambda \Omega \rho \imath \tau \varepsilon(\rho \varepsilon \delta 3, Н \mathrm{IГH})$;

$$
1=\mathrm{ON}
$$

Key: $\mathrm{R}=$ Red, $\mathrm{Y}=$ Yellow, $\mathrm{G}=$ Green, $\mathrm{N}=$ North, $\mathrm{E}=$ East,

$$
\mathrm{W}=\mathrm{West}
$$

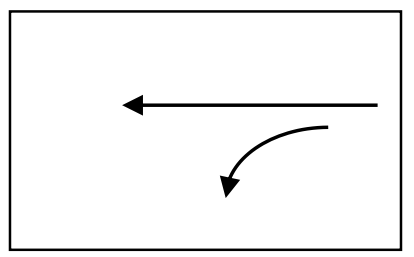

Fig.4: North Lane evaluation

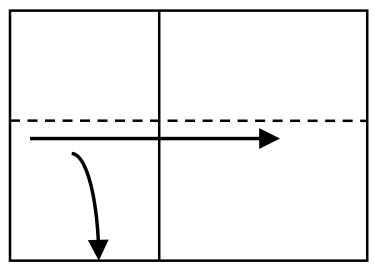

Fig.5: East lane evaluation

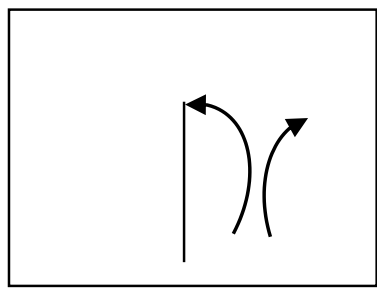

Fig.6: East lane evaluation

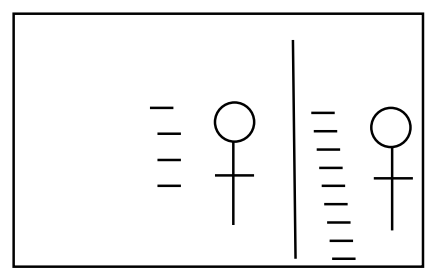

Fig.7: Pedestrians lane of evaluation

\subsection{Results of the Simulation}

After the assembling of the various components and the programming of the microcontroller traffic light control system, the following results were achieved:

(1) Automatic ON and OFF operation of the traffic light at the specified time

(2) Movement assignment to the busiest lane.

The performance evaluation of the traffic system was carried out, the model testing was performed at different occasions of light changing and the results below were achieved.

Initial time of operation of all the lanes $=550000 \mathrm{~ms}$ (i.e. 65 seconds)

\section{Red duration $\quad=15,000 \mathrm{~ms}$ \\ Yellowing duration of blinking ten times each of $=10,000 \mathrm{~ms}$}

$>$ Green duration $=30,000 \mathrm{~ms}$ 


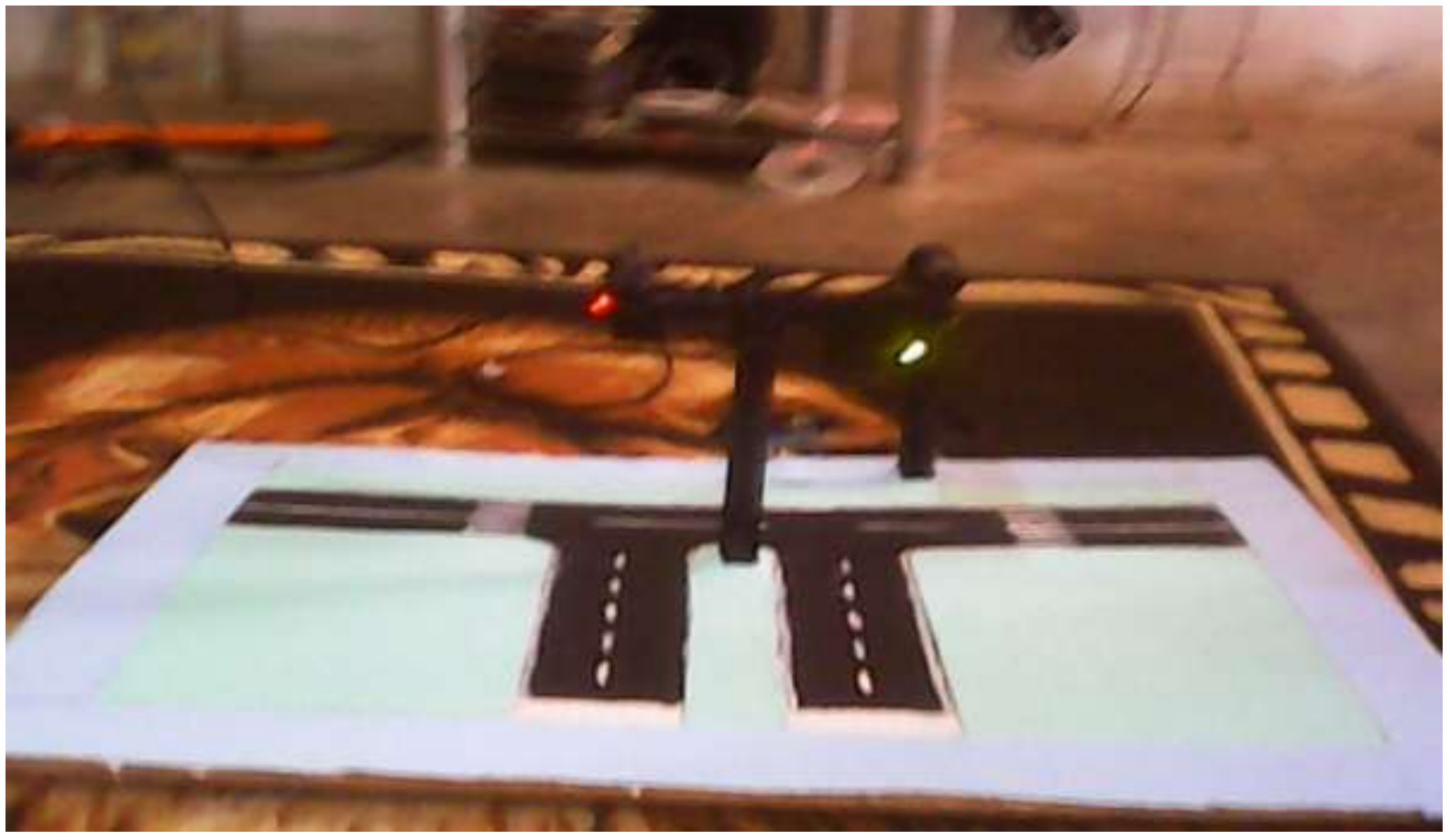

Fig.8: Output stand from the east (stand three)

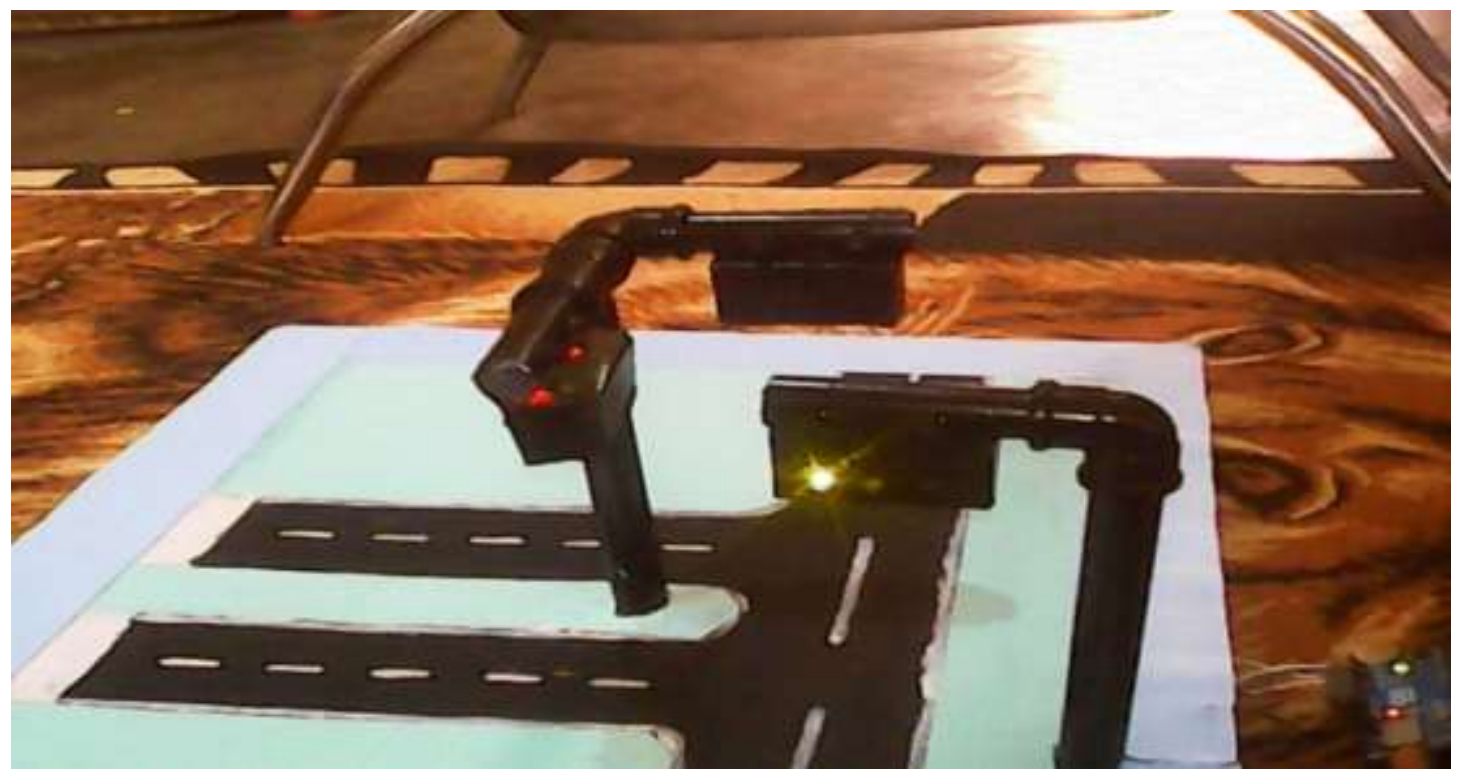

Fig. 9: Output view from the north (stand one)

\subsection{CONCLUSION}

This work showed the practical application of simulation of traffic lights to improve traffic conditions. Traffic is a challenge in many cities of the world. Traffic flow is dictated by certain devices such as traffic lights. These traffic lights signal when each lane is able to pass through the intersection. The purpose of this work was to find a way to make intersections to be easily controlled with traffic lights. This goal was accomplished through the simulation of traffic lights using Arduino Uno environment and programmed with $\mathrm{C}++$ programming language. From the design and construction of a simulated N-way traffic light controller carried out in the course of this work, it is obvious that such a system which if fully implemented will reduce the human stress of standing under favourable or unfavourable weather condition and controlling the movement of vehicles and pedestrians at $\mathrm{N}$-way traffic intersections. Generally, this work also encourages the producing of an indigenous traffic control system which is easy to maintain, affodable and efficient in operation. 


\section{REFERENCES}

[1] Mcshane, C (1999). The Origins and Globalization of Traffic Control Signals, Journal of Urban History / March, $1999 . \quad$ Retrieved from http://sites.tufts.edu/carscultureplace2010/files/2010/0 9/McShane-traffic-signals-1999.pdf

[2] Anonymous (2014). Driving In America. Retrieved from http://whatisusa.info/driving-in-america/

[3] Bellis, M (2014). "The History of Roads and Asphalt". Retrieved from http://inventors.about.com/od/rstartinventions/a/Histor y-Of-Roads.htm

[4] Masters, N (2013). CityDig: Should I Stop or Should I Go? Early Traffic Signals in Los Angeles, Los Angeles Magazine.

[5] Robert L., Gordon, P.E and Warren Tighe, P.E (2005). Traffic Control Systems Handbook, Office of Transportation Management Federal Highway Administration Room 3404 HOTM 400 Seventh Street Washington, D.C. 20590.

[6] Magomedov, T. G and Ostrovskiy, A. B (2006). Simulation of Smart Traffic Lights, Saint-Petersburg State University of Information Technologies, Mechanics and Optics Computer Technologies Department.

[7] Ferando, E. (2009). Microcontrollers Fundamentals and Applications, New York: CRC Press \& Francis Group.

[8] Greenfield, J. (2000). Digital Design using Integrated Circuits, New York: Willey and Sons Incorporation.

[9] Mehta, V. (2008). Principles of Electronics. New Delhi: Chand Company.

[10] Morris, M. (2007). Digital Logic and Computer Design, New Delhi: Practice Hall of India.

[11] Mayank (2011). Getting Started, Microcontrollers, http://maxembedded.com/2011/06/mcu-vs-mpu/

[12] http://maxembedded.com/2011/06/mcu-vs-mpu/

[13] https://www.arduino.cc/en/Reference/Board 